\title{
Crigler - Najjar Syndrome Type 2: A Usual Presentation of a Rare Disease
}

\author{
Burli Prithvi ${ }^{1}$, Habib Pathan ${ }^{2 *}$, Muhammad Junaid ${ }^{1}$, Khaja Amer Khan ${ }^{1}$ and Syed Taha ${ }^{1}$ \\ ${ }^{1}$ Senior Resident, Deccan College of Medical Sciences, India
}

${ }^{2}$ Professor of Pediatrics, Deccan College of Medical Sciences, India

*Corresponding author: Habib Pathan, Professor of Pediatrics, Deccan College of

Medical Sciences, Hyderabad, India.

\begin{abstract}
Crigler - Najjar syndrome (CN) type 2 is caused by a partial defect in uridine diphosphate glucoronosyl transferase-1 (UGT1A1) activity. It is characterized by isolated clinical jaundice. A clinical diagnosis may be confirmed by a detailed history and a thorough clinical evaluation. It needs to be differentiated from Gilbert syndrome. The hallmark of this benign condition is abnormally high unconjugated hyperbilirubinemia and its prompt response to oral phenobarbital therapy with excellent prognosis. Needless investigations should be avoided. Enzyme and gene testing could increase financial constraints in benign disease. We report one such case.
\end{abstract}

Background: Non-hemolytic unconjugated hyperbilirubinemia is a disorder of bilirubin conjugation, characterized by a nearly complete lack of UGT1A1 enzyme activity resulting in severe, even life-threatening symptoms (Crigler - Najjar syndrome type 1, CN type 1); or by partial enzyme activity and milder symptoms (Crigler - Najjar type 2,CN type 2 or Gilbert's syndrome, GS). It is caused by mutation in the gene UGT1A1 located on the long arm (q) of chromosome 2 (2q37) [1,2].

Crigler - Najjar syndrome is a rare disease with only few 100 cases described in the literature. Its incidence is estimated to be 1 in 1,000,000 births. The more common inherited unconjugated hyperbilirubinemia, GS, affects approximately 3-7\% of adult population $[1,2]$.

Disorders that causes unconjugated hyperbilirubinemia can be either result of excessive bilirubin production (hemolysis), or decreased clearance of bilirubin (hepatic or intestinal), or may be combinations of both [1,2]. Unconjugated bilirubin (bond to albumin, water-insoluble), is rapidly and selectively taken up by hepatocytes, converted, to bilirubin glucuronide, conjugates (water-soluble) and ultimately secreted into bile. In affected individuals, bilirubin conjugation is inhibited, resulting in abnormally high levels of unconjugated bilirubin in the blood (hyperbilirubinemia) [1-3].

Case presentation: In this report, we present a girl with recurrent episodes of non-hemolytic hyperbilirubinemia with high unconjugated bilirubin levels that decreased after phenobarbital treatment.

\section{Case Report}

A 9-years-old, school going girl, student of 4th standard, who was the second child of a third- degree consanguineous marriage, born as full term with birth weight of $2800 \mathrm{~g}$. She got admitted in our unit with complains of fever and yellowish discoloration of skin and sclera for 15 days. She had history of neonatal jaundice on day three of life for which phototherapy was given and jaundice subsided gradually in 24 hours. No exchange transfusion was required. She

had history of intermittent episodes of jaundice, appeared during concurrent phase of illness and subsided gradually without any serious symptoms like bleeding or any signs of liver cell failure. She did not require any blood transfusion. She had no such similar history in the family. She attained all developmental milestones at an appropriate age. She was immunized up to 2 years of age according to National Immunization schedule. On examination, 
child was well built and only had icterus. On systemic examination, there was no organomegaly.

Baseline investigations along with hemolytic work up were sent. Investigations showed hemoglobin of $12.5 \mathrm{~g} / \mathrm{dl}$, total leukocyte count of $7,000 / \mathrm{mm} 3$ and a platelet count of 2.49 lac/ $\mathrm{mm} 3$ with a reticulocyte count of $1 \%$, peripheral smear does not reveal hemolysis. Normal levels of serum Lactate Dehydrogenase $(\mathrm{LDH})(228 \mathrm{U} / \mathrm{l})$ and direct coombs test was negative, confirms no evidence of ongoing hemolysis.

Liver function tests revealed rise in total bilirubin of $12.6 \mathrm{mg} / \mathrm{dl}$, of which the indirect (unconjugated) component was $12 \mathrm{mg} / \mathrm{dl}$ and direct (conjugated) fraction was $0.6 \mathrm{mg} / \mathrm{dl}$. Liver enzymes, AST : 34 U/L, ALT : $21 \mathrm{U} / \mathrm{L}$, were essentially normal. Urine analysis shows no bile salts and pigments, indicating non-hemolytic unconjugated hyperbilirubinemia.

Based on the disease course and isolated unconjugated hyperbilirubinemia, the patient was suspected to have an inherited disorder of bilirubin conjugation and a provisional diagnosis of non-hemolytic unconjugated hyperbilirubinemia was made. More likely to be $\mathrm{CN}$ type 2 was considered more likely because serum bilirubin was more than $6 \mathrm{mg} / \mathrm{dl}$ and a therapeutic trial of oral phenobarbitone was given. Child was started empirically on oral phenobarbital at $5 \mathrm{mg} / \mathrm{kg} /$ gay (120 $\mathrm{mg}$ ) and then discharged and was followed up after 2 weeks. Post phenobarbitone therapy her total serum bilirubin reduced to $3.3 \mathrm{mg} / \mathrm{dl}$ of which conjugate component was $2 \mathrm{mg} / \mathrm{dl}$ and unconjugated was $1.3 \mathrm{mg} / \mathrm{dl}$.

\section{Discussion}

With a normal life expectancy and inherited in an autosomal recessive manner, a benign unconjugated hyperbilirubinemia are of two types. A partial mutation results in defective UGT1A1 enzyme activity level leading to: CN type 2, first described by Arias in 1962, presents with episodes of jaundice in the first decade of life, exacerbated by concurrent illness, stress, pregnancy or drug use, or, GS predominantly occurring in adulthood and rarely presents because of clinical jaundice and is usually discovered on a routine investigations done for another purpose [4-6].

The most reasonable approach to unconjugated hyperbilirubinemia is 1 ) to rule out intravascular hemolysis, 2) to differentiate disorders of bilirubin conjugation and 3) therapeutic response to phenobarbitone $[7,8]$.

In our case, a normal reticulocyte count and no hemolysis on peripheral smear, and a high unconjugated hyperbilirubinemia, conveniently, ruled out intravascular hemolysis $[7,8]$. The next step is to differentiate the disorders of bilirubin conjugation (GS and CN type 2). We differentiated CN type 2 from GS on basis of: 1) age of onset 2) unconjugated bilirubin levels 3) therapeutic response 4) treatment and 5) UGT1A1 enzyme activity [7-9] (Table 1).

Table 1

\begin{tabular}{|c|c|c|}
\hline & Crigler Najjar Syndrome & Gilbert Syndrome \\
\hline Age on onset & First decade of life & $</=6 \mathrm{mg} / \mathrm{dl}$ \\
\hline Unconjugated bilirubin levels & High $(<20 \mathrm{mg} / \mathrm{dl})$ & Normalizes \\
\hline Therapeutic response to phenobarbitone & Usually bilirubin falls $>30 \%$ but never normalize & None \\
\hline Treatment & Phenobarbitone & $>30 \%$ \\
\hline UGT1A1 Enzyme activity & $<10 \%$ & \\
\hline
\end{tabular}

Phenobarbitone is a microsomal enzyme inducer which lowers serum bilirubin levels $[1,9]$. Oral phenobarbitone was administered at $5 \mathrm{mg} / \mathrm{kg} /$ day (120 mg) and response was monitored by the fall in the level of unconjugated bilirubin and response is seen within two weeks, which may show completely normal level (Gilbert's syndrome), reduce $>30 \%$ (CNS 2) or nil effect (CNS 1). In our child, total serum bilirubin reduced to $3.3 \mathrm{mg} / \mathrm{dl}$ of which conjugate component was $2 \mathrm{mg} / \mathrm{dl}$ and unconjugated was $1.3 \mathrm{mg} / \mathrm{dl}$ after 2 weeks of phenobarbital therapy which is suggestive of Crigler Najjar syndrome 2.

Our child being a female child, pregnancy may induce stress and is the most common exacerbating factor during her adulthood. Pregnancy has a therapeutic challenge because of teratogenic side effects of phenobarbitone therapy, hence, the dose is reduced (30$60 \mathrm{mg} /$ day) but is not contraindicated. Prompt recognition and interdisciplinary involvement of specialists' team (Pediatrician,
Obstetrician, and Gastroenterologists) is essential. Clofibrate, a lipid-lowering agent, has proven to be a favorable replacement with similar efficacy and lesser side effects [9].

Plasmapheresis or phototherapy is restrained to prevent the transplacental transmission of bilirubin during pregnancy in female adults and to overcome hyperbilirubinemia crisis and a high risk of kernicterus to the fetus $[4,9]$.

Genetic counseling, adjuvant therapy with calcium supplements (increases gut excretion of bilirubin) and avoidance of drugs that displace bilirubin from albumin (penicillin, sulphonamides, salicylates, ceftriaxone and furosemide) should be done [4,9].

\section{Conclusion}

In conclusion, benign non-hemolytic unconjugated hyperbilirubinemia has an excellent prognosis. Prompt clinical evaluation and its distinctive features can avoid irrelevant 
investigation. Genetic analysis and enzyme assay may not add anything to management.

\section{Acknowledgement}

None.

\section{Conflict of Interest}

No conflict of interest.

\section{References}

1. Naureen Memon, Barry I Weinberger, Thomas Hegyi, Lauren M Aleksunes (2016) Inherited Disorders of Bilirubin Clearance. Pediatr Res 79(3): 378-386.

2. Watchko JF, Tiribelli C (2013) Bilirubin-induced neurologic damage-mechanisms and management approaches. N Engl J Med 369(21): 20212030.

3. Serge Erlinger, Irwin M Arias, Daniel Dhumeaux (2014) reviews in basic and clinical gastroenterology and hepatology. Gastroenterology 146 $1625-1638$
4. Crigler Najjar Syndrome in national organization of rare disease (NORD) 55 Kenosia Ave., Danbury CT 06810, (203)744-0100.

5. Arias IM (1962) Chronic unconjugated hyperbilirubinemia without overt signs of hemolysis in adolescents and adults. J Clin Invest 41(12): 2233-2245.

6. Piyush Ranjan, Sudha Kohli, Renu Saxena, Seema Thakur (2011) Mutation Analysis in Crigler - Najjar Syndrome Type II -Case Report and Literature Review. Journal of Clinical and Experimental Hepatology 1(3): 204-206.

7. Sushant Mane, Ashwini Ronghe (2017) GILBERT SYNDROME: A CASE SERIES. Pediatric Oncall Journal 14(2): 41

8. Shakuntala PN, Poornima M, Padmalatha VV, Rao SR (2012) Successful Pregnancy Outcome In Maternal Crigler Najjar Syndrome Type II. Online J Health Allied Scs 11(3): 1-3.

9. Prabhat Kumar, Gargi Sasmal, Shreya Gupta, Renu Saxena, Sudha Kohli (2017) Crigler Najjar Syndrome Type 2 (CNS Type 2): An Unwonted Cause of Jaundice in Adults. Journal of Clinical and Diagnostic Research 11(7): OD05-OD06. 